BIOFARM

Jurnal Ilmiah Pertanian

ISSN Print: 0216-5430; ISSN Online: 2301-6442

Vol. 14, No. 1, April 2018

\title{
Upaya Peningkatan Produksi Buncis (Phaseolus Vulgaris L) dengan Defoliasi dan Pemberian Pupuk Phospat
}

\author{
Efforts to Increase Beans Production (Phaseolus vulgaris L) by Defoliating \\ and Giving Phosphate Fertilizers
}

Darus Triyanto* dan Eka Adi Supriyanto

Program Studi Agroteknologi, Fakultas Pertanian, Universitas Pekalongan

*Korespondensi Penulis: tiyannugroho11@gmail.com

\begin{abstract}
ABSTRAK
Penelitian ini bertujuan untuk mengetahui pengaruh defoliasi dan pemberian pupuk phospat serta interaksinya terhadap peningkatan produksi buncis (phaseolus vulgaris L.), Dilaksanakan di desa Karangsari, Karanganyar, Pekalongan. Rancangan percobaan yang digunakan adalah Rancangan Acak Kelompok (RAK) yang terdiri atas 2 faktor. Faktor pertama defoliasi (D), yaitu tanpa defoliasi, defoliasi 2 helai daun per rumpun, defoliasi 4 helai daun per rumpun. Faktor kedua dosis pupuk phospat (P), yaitu $0 \mathrm{~kg} \mathrm{SP36/ha} \mathrm{(kontrol),} 75 \mathrm{~kg} \mathrm{SP36/ha,} 150 \mathrm{~kg} \mathrm{SP36/ha,} 225 \mathrm{~kg} \mathrm{SP36/ha.} \mathrm{Variabel} \mathrm{pengamatan}$ meliputi pajang tanaman, jumlah cabang per tanaman, jumlah polong per tanaman sempel, panjang polong per tanaman sempel, berat brangksan, berat polong per tanaman sempel, berat polong per petak, jumlah bunga per tanaman sempel, panjang akar terpanjang, berat akar per tanaman sempel. Hasil penelitian menunjukan bahwa defoliasi berpengaruh sangat nyata terhadap jumlah polong per tanaman sempel dan berat akar per tanaman sempel, berbeda nyata terhadap berat polong per tanaman sempel dan berat polong per petak. Perlakuan defoliasi terbaik adalah defoliasi 4 helai daun per rumpun (D2). Pemberian pupuk phospat (P) berbeda sangat nyata terhadap semua variabel pengamatan. Perlakuan dosis pupuk phospat terbaik adalah $150 \mathrm{~kg} \mathrm{SP36/ha} \mathrm{(P2).} \mathrm{Terdapat} \mathrm{interaksi} \mathrm{yang} \mathrm{sangat} \mathrm{nyata} \mathrm{antara} \mathrm{defoliasi} \mathrm{dengan}$ pemberian pupuk phospat terhadap variabel jumlah polong per tanaman sempel dan berat akar per tanaman sempel, dan berbeda nyata terhadap variabel panjang polong per tanaman sempel. Kombinasi terbaik diperoleh pada defoliasi 4 helai daun per rumpun dengan dosis pupuk phospat (P) $150 \mathrm{~kg} \mathrm{SP36/ha} \mathrm{(D2P2).}$
\end{abstract}

Kata kunci: buncis, defoliasi, phospat

\section{ABSTRACT}

This study aims to determine the effect of defoliation and phosphate fertilizer application and its interaction with the increased production of beans (Phaseolus vulgaris L.). Research conducted at the village Karangsari, Karanganyar, Pekalongan. The experimental design used was a Randomized Block Design using two factors. The first factor is without defoliation, defoliation 2 leaves per clump, defoliation 4 leaves per clump. The second factor of fertilizers, phosphate $(P)$ is $0 \mathrm{~kg} \mathrm{SP36/ha} \mathrm{(control),} 75 \mathrm{~kg}$ SP36/ha, $150 \mathrm{~kg} \mathrm{SP36/ha,} 225 \mathrm{~kg} S P 36 / \mathrm{ha}$. Variable observations include a display of plants, number of branches per plant, number of pods per plant sempel, long pods per plant sempel, heavy brangksan, weight of pods per plant sempel, weight of pods per plot, number of flowers per plant sempel, root length of the longest, heavy roots per sempel plants. The results showed that defoliation and significant effect on the number of pods per plant and weight of sample of sample of roots per plant, significantly different with the weight of pods per plant sempel and weight of pods per plot. Treatment is best defoliation defoliation 4 leaves per clump (D2). Provision of fertilizer, phosphate (P) highly significant for all variables observation. The treatment dose of fertilizer, phosphate $S P 36$ best was $150 \mathrm{~kg} / \mathrm{ha}$ (P2). There is a very real interaction of defoliation with phosphate fertilizer to variable sempel number of pods per plant and root weight per plant sempel, and significantly different with a variable length of pods per plant sempel. The best combination obtained in defoliation 4 leaves per clump with a dose of fertilizer, phosphate $(P) 150 \mathrm{~kg} \mathrm{SP36/ha} \mathrm{(D2P2).}$

Keywords: beans, defoliation, phospat

\section{PENDAHULUAN}

Tanaman buncis (Phaseolus vulgaris L.) berasal dari wilayah selatan Meksiko dan wilayah panas Guatemala. Pada kondisi liar, buncis ditemukan di dataran rendah hingga dataran tinggi, dan di lingkungan kering hingga lembab. Buncis berdaging kurang dapat beradaptasi terhadap iklim dibandingkan tipe biji kering, (Balai Penelitian Tanaman Sayuran, 2013).

Saat ini laju pertumbuhan penduduk semakin meningkat dan kesadaran gizi masyarakat semakin tinggi. Pertumbuhan penduduk membuat permintaan terhadap buncis meningkat. Data Deptan (2013) konsumsi sayuran di Indonesia adalah 40,35 
$\mathrm{kg} / \mathrm{kapita/tahun.} \mathrm{Selain} \mathrm{untuk} \mathrm{memenuhi} \mathrm{ke-}$ butuhan sayuran masyarakat Indonesia buncis juga di ekspor ke beberapa negara yaitu Singapura dan Jepang. Beberapa tahun terakhir ini Singapura memesan buncis Indonesia sekitar 2-3 ton perhari. Meskipun peluang pasar ekspor buncis ke Singapura cukup bagus, Indonesia hanya mampu mengirim 500-600 kg buncis per hari. Total ekspor terbesar buncis terjadi pada tahun 2010 yaitu sebesar $1.844 .904 \mathrm{~kg}$ dengan nilai sebesar 628.722 US\$, walaupun tahun 2011 mengalami penurunan ekspor sehingga menjadi $1.361 .032 \mathrm{~kg}$, namun masih tetap tinggi dibandingkan dengan tahun sebelum 2010 (BPS, 2012).

Rukmana (2009), menyatakan bahwa rendahnya produksi dan produktivitas kacang buncis disebabkan oleh praktek budidaya yang kurang baik. Para petani umumnya tidak memperhatikan adanya kerimbunan tanaman kacang buncis sehingga daun satu dengan lainnya saling menaungi, akibatnya dapat menurunkan produksi kacang buncis.

Menurut Dewani (2000), buncis merupakan tanaman kacang-kacangan yang berdaun lebat sehingga daun-daunnya akan saling menaungi satu dengan yang lain. Untuk menghindari adanya saling menaungi antar daun-daun tersebut perlu adanya perlakuan khusus, yaitu defoliasi. Tindakan defoliasi bertujuan untuk meningkatkan intensitas cahaya matahari yang dapat diterima oleh tanaman, sehingga akan meningkatkan hasil tanaman. Budiastuti dkk., (1997) mengatakan bahwa penurunan intensitas cahaya matahari akibat adanya saling menaungi daun satu dengan yang lainnya dapat menurunkan hasil sebesar $40 \%$.

Menurut Novizan (2007) salah satu cara untuk meningkatkan produksi tanaman buncis adalah dengan pemupukan. Pupuk didefinisikan sebagai material yang ditambahkan ke tanah atau tajuk tanaman dengan tujuan melengkapi ketersediaan unsur hara yang diserap tanaman untuk menunjang kehidupannya. Pemupukan phospat merupakan salah satu yang diperlukan oleh tanaman, dengan perkembangan akar yang lambat atau terhambat, dan tanaman yang seluruh bagiannya dipanen, contoh tanaman yang perlu phospat dalam jumlah besar adalah kacangkacangan. Pupuk phospat hampir tidak bersifat mobil (mudah berpindah), sehinga pupuk $P$ tetap berada ditempat semula selama musim tanam. Pemupukan phospat dapat merangsang pertumbuhan awal bibit tanaman, merangsang pembentukan bunga, buah, dan biji, bahkan mampu mempercepat proses pemasakan buah dan membuat biji lebih bernas. Penelitian ini dilakukan dengan tujuan untuk mengetahui pengaruh defoliasi dalam meningkatkan produksi buncis, untuk mengetahui dosis pupuk phospat yang optimum dalam meningkatkan buncis, dan untuk mengetahui interaksi antara defoliasi dengan pemberian dosis pupuk phospat terhadap produksi buncis.

\section{BAHAN DAN METODE}

Penelitian telah dilaksanakan di Desa Karangsari, Kecamatan Karanganyar, Kabupaten Pekalongan dengan ketinggian tempat \pm 81 meter di atas permukaan laut ( $\mathrm{m}$ dpl), dengan jenis tanah latosol pada bulan Oktober 2015 sampai Januari 2016. Rancangan yang digunakan dalam penelitian ini adalah Rancangan Acak Kelompok (RAK). Perlakuan yang akan dicoba ada 3 taraf Jumlah Defoliasi (D) dan 4 Dosis Pupuk Phospat $(\mathrm{P})$, yaitu: Defoliasi (D), terdiri atas, D0: Tanpa defoliasi, D1: Defoliasi 2 helai daun per rumpun, D2: Defoliasi 4 helai daun per rumpun, Dosis Pupuk Phospat (K), terdiriatas, P0: dosis $0 \mathrm{~kg} \mathrm{SP36/ha} \mathrm{(kontrol),}$ P1: dosis75 kg SP36/ha, P2: dosis $150 \mathrm{~kg}$ SP36/ha, P3: dosis $225 \mathrm{~kg}$ SP36/ha. Kombinasi perlakuan terdapat 16 kombinasi, masing-masing kombinasi diulang 3 kali sehingga ada $(3 \times 4) \times 3=36$ satuan pecobaan.

Data yang diperoleh dianalisis dengan uji F. Jika antara faktor yang dicoba terdapat perbedaan nyata maka analisis datanya dilanjutkan dengan uji Beda Nyata Terkecil (BNT), dan untuk faktor perlakuan defoliasi dilakukan uji kontras ortogonal, sedangkan faktor perlakuan dosis pupuk phospat dilakukan uji regresi. Variabel yang diamati meli- 
puti : Panjang Tanaman (cm), Jumlah Cabang per Tanaman (buah), Jumlah Polong per Tanaman sempel (buah), Panjang Polong per Tanaman sempel (cm), Berat Brangkasan $(\mathrm{g})$, Berat Polong per Tanaman sempel (g), Berat Polong per Petak $(\mathrm{kg})$, Jumlah Bunga per Tanaman sempel (buah), Panjang Akar Terpanjang $(\mathrm{cm})$, Berat Akar per Tanaman sampel ( $\mathrm{g})$.

\section{HASIL DAN PEMBAHASAN}

Matrik hasil analisis data penelitian upaya peningkatan produksi buncis (Phaseolus vulgaris L.) dengan defoliasi dan pemberian pupuk phospat disajikan pada Tabel 2. Angka rata-rata dan analisis statistik data penelitian penelitian upaya peningkatan produksi buncis (Phaseolus vulgaris L.) dengan defoliasi dan pemberian pupuk phospat disajikan pada Tabel 3. Data lengkap rata-rata hasil pengamatan dan analisis sidik ragam untuk setiap variabel yang diamati dapat dilihat pada lampiran 5 sampai dengan 14 .

\section{Pengaruh defoliasi}

Hasil penelitian menunjukkan bahwa pengaruh defoliasi sangat berbeda nyata terhadap jumlah polong per tanaman sampel, hasil tertinggi dicapai oleh perlakuan defoliasi 4 helai daun per rumpun, hal ini disebabkan pada saat defoliasi bertepatan saat tanaman buncis melakukan fase vegetatif, daun lebih lebat dan saling menaungi sehingga dengan defoliasi 4 helai daun dapat mengurangi persaingan daun dalam memperoleh cahaya matahari, Harjadi (2003) menyatakan bahwa faktor yang mempengaruhi produksi tanaman salah satunya adalah kecilnya persaingan daun untuk mendapatkan ruang tumbuh, cahaya matahari, $\mathrm{CO}_{2}$, unsur hara dan air. Apabila faktor yang mempengaruhi pertumbuhan tersebut optimal, maka hasil yang diperoleh akan meningkat. Pendapat ini didukung oleh Heddy dkk., (1990) yang menyatakan bahwa pengurangan daun pada tanaman kacang-kacangan cenderung memberikan kenaikan jumlah polong, hal ini disebabkan jumlah intensitas cahaya yang masuk pada kanopi tanaman cenderung meningkat, dan metabolisme tanaman pun juga meningkat, akibatnya asimilat yang dihasilkan juga bertambah. Asimilat tersebut kemudian ditranslokasikan ke cadangan makanan yaitu polong, maka polong yang terbentukpun menjadi bertambah banyak.

Tabel 1. Matrik Hasil Analisis Data Penelitian Pengaruh Upaya Peningkatan Produksi Buncis (Phaseolus vulgaris L.) dengan Defoliasi dan Pemberian Pupuk Phospat.

\begin{tabular}{|c|c|c|c|c|}
\hline \multirow[b]{2}{*}{ No. } & \multirow[b]{2}{*}{ Variabel yang diamati } & \multicolumn{3}{|c|}{ Faktor yang dicoba } \\
\hline & & Defoliasi & $\begin{array}{c}\text { Pemberian } \\
\text { pupuk phospat }\end{array}$ & Interaksi \\
\hline 1 & Panjang tanaman $(\mathrm{cm})$ & th & ** & th \\
\hline 2 & Jumlah cabang pertanaman (buah) & tn & ** & tn \\
\hline 3 & Jumlah polong per tanaman sampel (buah) & ** & ** & ** \\
\hline 4 & Panjang polong per tanaman sampel $(\mathrm{cm})$ & tn & ** & * \\
\hline 5 & Berat brangkasan $(\mathrm{g})$ & tn & ** & tn \\
\hline 6 & Berat polong per tanaman sampel $(\mathrm{g})$ & * & ** & tn \\
\hline 7 & Berat polong per petak $(\mathrm{kg})$ & * & ** & tn \\
\hline 8 & Jumlah bunga per tanaman sampel (buah) & tn & ** & tn \\
\hline 9 & Panjang akar terpanjang $(\mathrm{cm})$ & tn & ** & tn \\
\hline 10 & Berat akar per tanaman sampel (g) & ** & ** & ** \\
\hline
\end{tabular}

Keterangan:

${ }^{* *}$ : Berbeda sangat nyata, ${ }^{*}$ : Berbeda nyata, tn : Tidak berbeda nyata

\section{Pengaruh dosis pupuk phospat}

Hasil penelitian menunjukan bahwa pengaruh dosis pupuk phospat $(\mathrm{P})$ sangat berbeda nyata terhadap panjang tanaman dan jumlah cabang per tanaman hasil tertinggi dicapai oleh perlakuan dosis pupuk phospat $150 \mathrm{~kg} \mathrm{SP36/ha,} \mathrm{hal} \mathrm{ini} \mathrm{disebabkan}$ peranan unsur $\mathrm{P}$ dalam proses pembelahan dan pembesaran sel. Unsur P merupakan unsur hara makro yang diperlukan oleh tanaman, yang berperan penting dalam berbagai proses kehidupan seperti fotosintesis, respirasi, transfer dan penyimpanan energi, pembelahan dan pembesaran sel, dan metabolisme karbohidrat dalam tanaman (Salisbury dan Ross, 1995). Lakitan (1996), 
pertumbuhan tinggi tanaman ditentukan oleh perkembangan dan pertumbuhan sel. Semakin cepat sel membelah dan memanjang (membesar) semakin cepat tanaman meninggi. Pertumbuhan tinggi tanaman terjadi di dalam meristem interkalar pada ruas yang memanjang sebagai akibat meningkatnya jumlah sel dan terutama karena meluasnya sel. Sehingga dengan adanya pembelahan, pemanjangan dan pembesaran sel maka perubahan tinggi tanaman yang makin memanjang dan terbentuknya jumlah cabang tanaman.

Tabel 2. Angka Rata-Rata dan Analisis Statistik Data Penelitian Upaya Peningkatan Produksi Buncis (Phaseolus vulgaris L.) dengan Defoliasi dan Pemberian Pupuk Phospat

\begin{tabular}{|c|c|c|c|c|c|}
\hline Perlakuan & $\begin{array}{l}\text { Panjang } \\
\text { tanaman } \\
(\mathrm{cm})\end{array}$ & $\begin{array}{c}\text { Jumlah } \\
\text { cabang per } \\
\text { tanaman } \\
\text { (buah) }\end{array}$ & $\begin{array}{l}\text { Jumlah polong } \\
\text { per tanaman } \\
\text { sampel } \\
\text { (buah) }\end{array}$ & $\begin{array}{l}\text { Panjang polong } \\
\text { per tanaman } \\
\text { sampel } \\
\text { (cm) }\end{array}$ & $\begin{array}{c}\text { Berat } \\
\text { brangkasan } \\
\text { (g) }\end{array}$ \\
\hline \multicolumn{6}{|l|}{ Defoliasi } \\
\hline D0 = Tanpa Defoliasi & 204,23 & 8,23 & $15,41 \mathrm{a}$ & 14,65 & 126,07 \\
\hline $\begin{array}{l}\text { D1 = Defoliasi } 2 \text { helai daun } \\
\text { per rumpun }\end{array}$ & 204,92 & 8,32 & $19,20 \mathrm{~b}$ & 14,80 & 126,03 \\
\hline $\begin{array}{l}\text { D2 = Defoliasi } 4 \text { helai daun } \\
\text { per rumpun }\end{array}$ & 205,45 & 8,48 & $20,21 \mathrm{c}$ & 14,97 & 126,63 \\
\hline F hitung & $2,48 \mathrm{tn}$ & 0,54 tn & $2587,88^{\star *}$ & $0,65 \mathrm{tn}$ & 2,63 tn \\
\hline F tabel 5\% & 3,44 & 3,44 & 3,44 & 3,44 & 3,44 \\
\hline F tabel $1 \%$ & 5,72 & 5,72 & 5,72 & 5,72 & 5,72 \\
\hline BNT 5\% & & - & 0,15 & - & - \\
\hline KK (\%) & 0,65 & 7,11 & 0,94 & 4,61 & 0,57 \\
\hline \multicolumn{6}{|l|}{ Dosis Pupuk Phospat (P) } \\
\hline $\mathrm{PO}=0 \mathrm{~kg} / \mathrm{ha}$ & $194,11 \mathrm{a}$ & $6,02 \mathrm{a}$ & $14,38 \mathrm{a}$ & $10,12 \mathrm{a}$ & $118,80 a$ \\
\hline $\mathrm{P} 1=75 \mathrm{~kg} / \mathrm{ha}$ & $208,13 b$ & $9,40 \mathrm{~b}$ & $19,44 \mathrm{~b}$ & $14,58 \mathrm{~b}$ & $129,98 \mathrm{~b}$ \\
\hline $\mathrm{P} 2=150 \mathrm{~kg} / \mathrm{ha}$ & $214,40 \mathrm{c}$ & $10,38 \mathrm{c}$ & $21,60 \mathrm{c}$ & $18,87 \mathrm{c}$ & $135,44 \mathrm{c}$ \\
\hline$P 3=225 \mathrm{~kg} / \mathrm{ha}$ & $202,82 d$ & $7,67 d$ & $17,67 \mathrm{~d}$ & $15,65 d$ & $120,76 \mathrm{~d}$ \\
\hline F hitung & $369,71^{* *}$ & $93,99^{\star *}$ & $2814,73^{\star \star}$ & $252,71^{\star *}$ & $1066,20^{\star *}$ \\
\hline$F$ tabel $5 \%$ & 3,05 & 3,05 & 3,05 & 3,05 & 3,05 \\
\hline $\mathrm{F}$ tabel $1 \%$ & 4,82 & 4,82 & 4,82 & 4,82 & 4,82 \\
\hline BNT 5\% & 1,31 & 0,58 & 0,17 & 0,58 & 0,70 \\
\hline KK (\%) & 0,65 & 7,11 & 0,94 & 4,61 & 0,57 \\
\hline
\end{tabular}

Keterangan:

Angka-angka dalam kolom dan perlakuan yang diikuti dengan huruf yang sama menunjukkan tidak berbeda nyata berdasarkan Uji BNT pada taraf $5 \% .{ }^{* *}=$ Berbeda sangat nyata, ${ }^{*}=$ Berbeda nyata, $\mathrm{tn}=$ Tidak berbeda nyata.

\section{Pengaruh interaksi antara defoliasi de- ngan dosis pupuk phospat $(P)$}

Hasil penelitian menunjukkan bahwa terjadi interaksi antara defoliasi dengan dosis pupuk phospat (P) terhadap variabel jumlah polong per tanaman sempel dan panjang polong per tanaman sempel. Kombinasi terbaik adalah pada perlakuan defoliasi 4 helai daun per rumpun dengan dosis pupuk phospat $150 \mathrm{~kg} \mathrm{SP} 36 / \mathrm{ha}$ (D2P2), hal ini terjadi disebabkan adanya hubungan saling mendukung yaitu dengan adanya defoliasi 4 helai daun perumpun makan dapat mengurangi kerimbunan daun sehingga daun tidak saling menaungiakan mempunyai kesempatan yang lebih besar dalam memanfaatkan cahaya matahari yang ditangkap oleh daun untuk digunakan sebagai energi dalam proses fotosintesis, sehingga hasil fotosintesisnya (fotosintat) juga akan lebih baik. Fotosintat inilah yang nantinya digunakan oleh tanaman untuk pertumbuhan tanaman buncis dan pada masa generatif akan dialokasikan untuk pembentukan polong buncis (Rizqiani, 2007). Didukung dengan pemberian pupuk phospat maka fotosistesis dapat berjalan dengan lancar sehingga pembentukan polong buncis dapat lebih banyak dan lebih panjang. Phospat sebagai zat makanan sangat penting dalam proses fisiologis didalam tanaman yaitu dalam proses fotosintesa dan respirasi (Rinsema, 1995). 
Tabel 3. Angka Rata-Rata dan Analisis Statistik Data Penelitian Upaya Peningkatan Produksi Buncis (Phaseolus vulgaris L.) dengan Defoliasi dan Pemberian Pupuk Phospat

\begin{tabular}{|c|c|c|c|c|c|}
\hline Perlakuan & $\begin{array}{l}\text { Berat polong } \\
\text { per tanaman } \\
\text { sampel } \\
\text { (g) }\end{array}$ & $\begin{array}{c}\text { Berat } \\
\text { polong per } \\
\text { petak } \\
(\mathrm{kg}) \\
\end{array}$ & $\begin{array}{c}\text { Jumlah bunga } \\
\text { per tanaman } \\
\text { sampel } \\
\text { (buah) }\end{array}$ & $\begin{array}{c}\text { Panjang } \\
\text { akar } \\
\text { terpanjang } \\
(\mathrm{cm}) \\
\end{array}$ & $\begin{array}{c}\text { Berat akar per } \\
\text { tanaman } \\
\text { sampel } \\
\text { (g) }\end{array}$ \\
\hline \multicolumn{6}{|l|}{ Defoliasi } \\
\hline D0 = Tanpa Defoliasi & $84,35 a$ & $2,36 \mathrm{a}$ & 17,97 & 13,35 & $1,04 \mathrm{a}$ \\
\hline $\begin{array}{l}\mathrm{D} 1 \text { = Defoliasi } 2 \text { helai daun } \\
\text { per rumpun }\end{array}$ & $102,90 \mathrm{~b}$ & $2,61 \mathrm{~b}$ & 18,25 & 13,50 & $1,37 \mathrm{~b}$ \\
\hline $\begin{array}{l}\text { D2 = Defoliasi } 4 \text { helai daun } \\
\text { per rumpun }\end{array}$ & $113,63 \mathrm{c}$ & $2,84 \mathrm{c}$ & 18,18 & 13,80 & $1,92 \mathrm{c}$ \\
\hline F hitung & $3,97^{*}$ & $3,75^{\star}$ & 0,49 tn & $1,30 \mathrm{tn}$ & $607,15^{\star *}$ \\
\hline $\mathrm{F}$ tabel $5 \%$ & 3,44 & 3,44 & 3,44 & 3,44 & 3,44 \\
\hline $\mathrm{F}$ tabel $1 \%$ & 5,72 & 5,72 & 5,72 & 5,72 & 5,72 \\
\hline BNT 5\% & 14,22 & 0,37 & - & - & 0,05 \\
\hline KK (\%) & 16,22 & 16,57 & 4,04 & 5,13 & 4,14 \\
\hline \multicolumn{6}{|l|}{ Dosis Pupuk Phospat (P) } \\
\hline $\mathrm{PO}=0 \mathrm{~kg} / \mathrm{ha}$ & $93,02 \mathrm{a}$ & $2,33 a$ & $15,64 a$ & $10,64 \mathrm{a}$ & $0,99 a$ \\
\hline $\mathrm{P} 1=75 \mathrm{~kg} / \mathrm{ha}$ & $102,29 a b$ & $2,56 \mathrm{ab}$ & $18,82 \mathrm{~b}$ & $12,65 \mathrm{~b}$ & $1,57 \mathrm{~b}$ \\
\hline $\mathrm{P} 2=150 \mathrm{~kg} / \mathrm{ha}$ & $120,82 \mathrm{~b}$ & $3,07 \mathrm{~b}$ & $21,60 \mathrm{c}$ & $14,73 \mathrm{c}$ & $1,90 \mathrm{c}$ \\
\hline $\mathrm{P} 3=225 \mathrm{~kg} / \mathrm{ha}$ & $98,38 \mathrm{c}$ & $2,46 \mathrm{c}$ & $16,47 \mathrm{~d}$ & $16,17 \mathrm{~d}$ & $1,30 \mathrm{~d}$ \\
\hline F hitung & $4,65^{\star}$ & $5,19^{* *}$ & $120,12^{\star *}$ & $108,65^{\star *}$ & $382,34^{* *}$ \\
\hline F tabel $5 \%$ & 3,05 & 3,05 & 3,05 & 3,05 & 3,05 \\
\hline F tabel $1 \%$ & 4,82 & 4,82 & 4,82 & 4,82 & 4,82 \\
\hline BNT 5\% & 16,43 & 0,42 & 0,72 & 0,68 & 0,06 \\
\hline KK (\%) & 16,22 & 16,57 & 4,04 & 5,13 & 4,14 \\
\hline
\end{tabular}

Keterangan:

Angka-angka dalam kolom dan perlakuan yang diikuti dengan huruf yang sama menunjukkan tidak berbeda nyata berdasarkan Uji BNT pada taraf $5 \% .{ }^{* *}=$ Berbeda sangat nyata, ${ }^{*}=$ Berbeda nyata, $\mathrm{tn}=$ Tidak berbeda nyata.

Tabel 4. Angka Rata-Rata dan Analisis StatistikData Penelitian Upaya Peningkatan Produksi Buncis (Phaseolus vulgaris L.) dengan Defoliasi dan Pemberian Pupuk Phospat

\begin{tabular}{cccc}
\hline Kombinasi perlakuan & $\begin{array}{c}\text { Jumlah polong per } \\
\text { tanaman sampel } \\
\text { (buah) }\end{array}$ & $\begin{array}{c}\text { Panjang polong per } \\
\text { tanaman sampel } \\
(\mathrm{cm})\end{array}$ & $\begin{array}{c}\text { Berat akar per } \\
\text { tanaman sampel } \\
(\mathrm{g})\end{array}$ \\
\hline D0P0 & $13,89 \mathrm{a}$ & $9,68 \mathrm{a}$ & $0,91 \mathrm{a}$ \\
D0P1 & $14,92 \mathrm{c}$ & $14,18 \mathrm{~b}$ & $1,11 \mathrm{c}$ \\
D0P2 & $16,83 \mathrm{e}$ & $18,33 \mathrm{e}$ & $1,12 \mathrm{c}$ \\
D0P3 & $15,99 \mathrm{~d}$ & $16,40 \mathrm{~d}$ & $1,00 \mathrm{ab}$ \\
D1P0 & $14,53 \mathrm{~b}$ & $10,03 \mathrm{a}$ & $1,00 \mathrm{ab}$ \\
D1P1 & $20,37 \mathrm{~h}$ & $14,81 \mathrm{~b}$ & $1,48 \mathrm{~d}$ \\
D1P2 & $23,87 \mathrm{j}$ & $18,61 \mathrm{f}$ & $1,97 \mathrm{f}$ \\
D1P3 & $18,03 \mathrm{f}$ & $15,74 \mathrm{c}$ & $1,03 \mathrm{bc}$ \\
D2P0 & $14,72 \mathrm{bc}$ & $10,63 \mathrm{a}$ & $1,07 \mathrm{bc}$ \\
D2P1 & $23,03 \mathrm{i}$ & $14,73 \mathrm{~b}$ & $2,11 \mathrm{~g}$ \\
D2P2 & $24,11 \mathrm{j}$ & $19,67 \mathrm{~g}$ & $2,63 \mathrm{~h}$ \\
D2P3 & $19,00 \mathrm{~g}$ & $14,82 \mathrm{~b}$ & $1,86 \mathrm{e}$ \\
F hitung & $371,47^{* *}$ & $2,97^{*}$ & $70,91^{* *}$ \\
F tabel 5\% & 2,44 & 2,55 & 2,55 \\
F tabel 1\% & 3,76 & 3,76 & 3,76 \\
BNT 5\% & 0,29 & 2,97 & 0,10 \\
KK $(\%)$ & 0,94 & 4,61 & 4,35 \\
\hline
\end{tabular}

Keterangan:

Angka-angka dalam kolom dan perlakuan yang diikuti dengan huruf yang sama menunjukkan tidak berbeda nyata berdasarkan Uji BNT pada taraf $5 \% .{ }^{* *}=$ Berbeda sangat nyata, ${ }^{*}=$ Berbeda nyata, $\mathrm{tn}=$ Tidak berbeda nyata. 


\section{KESIMPULAN}

1. Defoliasi daun berpengaruh sangat nyata terhadap variabel jumlah polong per tanaman sempel dan berat akar per tanaman sempel, berbeda nyata terhadap berat polong per tanaman sempel dan berat polong per petak, sedangkan pada variabel panjang tanaman, jumlah cabang pertanaman, panjang tanaman pertanaman sempel, berat brangkasan, jumlah bunga pertanaman sempel dan panjang akar terpanjang tidak berpengaruh nyata. Defoliasi 4 helai daun per rumpun memberikan hasil terbaik pada pertumbuhan dan produksi tanaman buncis.

2. Dosis pupuk phospat $(\mathrm{P})$ berpengaruh sangat nyata terhadap semua variabel yang diamati. Pertumbuhan dan produksi buncis tertinggi dicapai pada dosis $150 \mathrm{~kg}$ SP36/ha.

3. Terdapat interaksi antara antara defoliasi dengan dosis pupuk phospat (P) terhadap jumlah polong per tanaman sempel, berat akar per tanaman sempel dan panjang polong per tanaman sempel. Kombinasi terbaik dicapai pada defoliasi 4 helai daun per rumpun dengan dosis pupuk phospat (P) $150 \mathrm{~kg}$ SP36/ha.

\section{DAFTAR PUSTAKA}

Balai Penelitian Tanaman Sayuran. 2013. Varietas-varietas Buncis Yang Telah Dilepas Oleh Balai Penelititan Tanaman Sayuran. Lembang,
Bandung.

Badan Pusat Statistik. 2012. Buletin Statistik Perdagangan Ekspor-Impor. BPS, Jakarta.

Dewani, M. 2000. Pengaruh Defoliasi Terhadap Pertumbuhandan Hasil Tanaman Kacang Hijau (Vignaradiata L) Varietas Waletdan Wongsorejo. Universitas Lampung. Habitat Vol. 11 No. 113 Desember 2000.

Budiastuti, Sumarno, dan Harjanti. 1997. Kesesuaian Pemberian Ajirdan Defoliasi pada Tanaman Kedelai Varietas Wilisdan Lakon dalam Majalah IImiah. Universitas Sebelas Maret Edisi Maret 1997, Vol XII No. 1. Fakultas Pertanian Universitas Sebelas Maret, Surakarta.

Novizan. 2007. Petunjuk Pemupukan yang Efektif. AgroMediaPustaka, Jakarta. Harjadi, S.S. 2003. Pengantar Agronomi. Gramedia, Jakarta.

Heddy, S. T. Wijono, dan W. Kusno. Pengaruh Pengurangan Daun (Defoliasi) terhadap Hasil Tanaman Kedelai pada Jarak Tanam Berbeda. Agrivita, Vol 13 (3) Agustus-Desember 1990.

Salisbury, F.B \& C.W. Ross. 1995. Fisiologi Tumbuhan. Bandung: ITB Press. Lakitan, B. 1996. Fisiologi Pertumbuhan dan Perkembangan Tanaman. P.T. Grafindo Persada. Jakarta.

Rizqiani, N.F. E. Ambarwati, dan N.W. Yuwono. 2007. Pengaruh Dosis dan Frekuensi Pemberian Pupuk Organik Cair terhadap Pertumbuhan dan Hasil Buncis (Phaseolus vulgaris L.) Dataran Rendah. Jurnal IImu Tanah dan Lingkungan, Vol. 7 (1) : 43-53.

Rinsema, W.T. 1995. Pupuk dan Cara Pemupukan. Bhatara Karya Aksara. Jakarta. 